\title{
ВЛИЯНИЕ УСЛОВИЙ ПОЛЗУЧЕСТИ И ДЛИТЕЛЬНОГО ОТЖИГА НА ОБРАЗОВАНИЕ ЧАСТИЦ $Z$-ФАЗЫ
}

\author{
(С) 2020 г. А. Э. Федосеева ${ }^{a, *}$, И. С. Никитин ${ }^{a}$, Н. Р. Дудова ${ }^{a}$, Р. О. Кайбышев ${ }^{a}$ \\ ${ }^{a}$ Белгородский государственный национальный исследовательский университет, \\ ул. Победы, 85, Белгород, 308015 Россия \\ *e-mail:fedoseeva@bsu.edu.ru \\ Поступила в редакцию 12.12.2019 г. \\ После доработки 12.02.2020 г. \\ Принята к публикации 13.02.2020 г.
}

\begin{abstract}
Влияние температуры, приложенного напряжения, степени деформации при ползучести и времени выдержки при длительном старении на образование частиц $Z$-фазы (CrVN) было изучено в $9 \% \mathrm{Cr}$ мартенситной стали 10Х9К3В2МФБР при температурах 650 и $675^{\circ} \mathrm{C}$. После ползучести при $650^{\circ} \mathrm{C} / 120 \mathrm{MПа} / 4869$ ч и $675^{\circ} \mathrm{C} / 120 \mathrm{MПа/773} \mathrm{ч} \mathrm{были} \mathrm{обнаружены} \mathrm{частицы} \mathrm{с} \mathrm{химическим} \mathrm{составом,}$ полученным методом энергодисперсионной спектрометрии как $50 \%(\mathrm{Cr}+\mathrm{Fe})$ и $50 \%(\mathrm{~V}+\mathrm{Nb})$, которые были идентифицированы как частицы $Z$-фазы. Увеличение времени испытания на ползучесть при обеих температурах привело к росту частиц $Z$-фазы. Повышение температуры провоцирует более раннее зарождение мелких частиц $Z$-фазы с изменением механизма их зарождения. Укрупнение частиц наблюдается при локализации пластической деформации. Длительный отжиг при температурах 650 и $675^{\circ} \mathrm{C}$ не приводит к образованию частиц $Z$-фазы. Пластическая деформация оказывает определяющее влияние на образование частиц $Z$-фазы в сталях, содержащих $9 \% \mathrm{Cr}$. Температура, время, приложенное напряжения, локализация деформации носят усугубляющий характер, вызывая укрупнение этой фазы.
\end{abstract}

Ключевые слова: жаропрочная сталь мартенситного класса, ползучесть, длительный отжиг, карбонитриды MX, $Z$-фаза, фазовое превращение

DOI: $10.31857 / \mathrm{S} 0015323020060054$

\section{ВВЕДЕНИЕ}

Развитие материалов для энергетического машиностроения направлено на увеличение кпд угольных электростанций за счет повышения жаропрочности [1-3]. В настоящее время вводятся в эксплуатацию энергоблоки, работающие при суперсверхкритических параметрах пара (ССКП): давление - 240-330 МПа, температура 620$650^{\circ} \mathrm{C}$. Эти параметры пара являются недосягаемыми при применении традиционных ферритных и бейнитных сталей [1]. Революционные изменения, которые произошли в материаловедении котельных и турбинных сталей 30 лет назад, связывают с разработкой нового поколения высокохромистых сталей мартенситного класса с содержанием $\mathrm{V} 0.24 \%$ и $\mathrm{Nb} 0.05 \%$ при содержании С $0.1 \%$ и $\mathrm{N} 0.05 \%$. Подобное легирование позволяет получить наноразмерные карбонитриды $\mathrm{M}(\mathrm{C}, \mathrm{N})$ (где M означает $\mathrm{V}, \mathrm{Nb}$ и/или Ta), не склонные к коагуляции при высоких температурах благодаря двухфазному разделению на VN и $\mathrm{NbC} \mathrm{[1-13]} \mathrm{и} \mathrm{обеспечивает} \mathrm{длительную} \mathrm{проч-}$ ность этих сталей, достаточную для повышения температуры пара на $40-70^{\circ} \mathrm{C}$. Равномерно по объему матрицы наноразмерные карбонитриды $\mathrm{M}(\mathrm{C}, \mathrm{N})$ выступают в качестве препятствий для движения дислокаций и их перестройки в субзеренные границы. Последнее приводит к резкому повышению скорости ползучести [14]. Однако, карбонитриды $\mathrm{M}(\mathrm{C}, \mathrm{N})$ являются неравновесной фазой, и в процессе эксплуатации замещаются равновесной $Z$-фазой $(\mathrm{Cr}(\mathrm{V}, \mathrm{Nb}) \mathrm{N})$, размер которой может достигать нескольких микрон [4-6, 12, 13]. Это увеличивает расстояние между частицами в процессе ползучести, что может быть важной причиной преждевременного наступления третичной стадии ползучести, уменьшающей долговременную прочность [4-9].

В предшествующих исследованиях был установлен механизм образования частиц $Z$-фазы в процессе ползучести при $650^{\circ} \mathrm{C}[6,12,13,15,16]$. Этот механизм заключался в прямой перестройке кубической решетки карбонитридов $\mathrm{M}(\mathrm{C}, \mathrm{N})$ в тетрагональную решетку $Z$-фазы. Процесс трансформации начинается с периферийной зоны частиц $\mathrm{M}(\mathrm{C}, \mathrm{N})$ и постепенно перемещается в направлении к их “ядру”, образуя так называемую “гибридную частицу”. Скорость укрупнения 
Cr-обогащенной “оболочки” из $Z$-фазы вдоль периферии частицы $\mathrm{M}(\mathrm{C}, \mathrm{N})$ контролируется диффузией атомов $\mathrm{Cr}$ из ферритной матрицы и атомов $\mathrm{V}$ или $\mathrm{Nb}$ из “ядра" частицы M(C,N) [5, 12, 13].

Цель настоящего исследования заключается в установлении роли таких факторов, как температура, приложенные напряжения, время испытания, деформация и величина ее локализации на превращение карбонитридов $\mathrm{M}(\mathrm{C}, \mathrm{N})$ в $Z$-фазу. Это информация позволит уточнить механизм и кинетику данного превращения, что позволит увеличить их характеристики жаропрочности.

\section{МЕТОДИКА \\ ПРОВЕДЕНИЯ ИССЛЕДОВАНИЙ}

Сталь 10Х9К3В2МФБР следующего химического состава, мас. \%: $\mathrm{Fe}$-баланс $-0.12 \mathrm{C}-0.06 \mathrm{Si}-$ $0.1 \mathrm{Ni}-0.2 \mathrm{Mn}-9.5 \mathrm{Cr}-3.2 \mathrm{Co}-0.45 \mathrm{Mo}-2.0 \mathrm{~W}-0.2 \mathrm{~V}-$ $0.06 \mathrm{Nb}-0.005 \mathrm{~B}-0.05 \mathrm{~N}$ была отлита в высокочастотной индукционной печи в ОАО НПО “ЦНИИТМАШ”. Слитки были перекованы на заготовки в виде прутков квадратного сечения со стороной квадрата 20 мм методом свободной ковки в интервале температур от 1150 до $900^{\circ} \mathrm{C}$. Термическая обработка стали состояла из нормализации с $(1050 \pm 10)^{\circ} \mathrm{C}$ с последующим отпуском в течение 3 ч при $(750 \pm 10)^{\circ} \mathrm{C}$. Плоские образцы с длиной рабочей части 25 мм и поперечным сечением $7 \times 3$ мм $^{2}$ и цилиндрические образцы с длиной рабочей части 100 мм и диаметром 10 мм были испытаны на длительную прочность до разрушения при температурах 650 и $675^{\circ} \mathrm{C}$ при приложенных напряжениях в интервале 180-80 МПа с шагом 20 МПа с использованием испытательной машины рычажного типа ATS2330.

Для проведения структурных исследований был использован просвечивающий электронный микроскоп JEM JEOL-2100 (ПЭМ), оснащенный энергодисперсионной приставкой INCA. Фольги для ПЭМ были изготовлены из захватной и рабочей части, а также из области шейки образцов на ползучесть и электролитически отполированы в электролите состава $10 \%$-ной хлорной кислоты в уксусной кислоте при комнатной температуре. Анализ углеродных реплик был произведен с целью определения точного химического состава частиц без влияния матрицы при получении энергодисперсионного спектра. Идентификация частиц вторичных фаз проводилась одновременно по анализу микродифракций, полученных в просвечивающем электронном микроскопе (ПЭМ), и химического состава частиц. Более подробно методики описаны в предыдущих работах $[8,9,15,16]$.

\section{РЕЗУЛЬТАТЫ ИССЛЕДОВАНИЯ}

Исходное состояние после отпуска при $750^{\circ} \mathrm{C}$. Микроструктура стали 10Х9К3В2МФБР, а также анализ карбонитридов $\mathrm{M}(\mathrm{C}, \mathrm{N})$ после нормализации и отпуска при $750^{\circ} \mathrm{C}$ были детально описаны в предыдущих работах $[8,9,15,16]$. Кратко следует отметить, что после термической обработки формируется реечная структура троостита отпуска с высокой плотностью дислокаций внутри мартенситных реек. Глобулярные карбиды $\mathrm{M}_{23} \mathrm{C}_{6}$ со средним размером 90 нм располагаются по границам исходных аустенитных зерен, мартенситных реек и субзерен, в то время как карбонитриды $\mathrm{M}(\mathrm{C}, \mathrm{N})$ равномерно распределены по объему ферритной матрицы. Два типа частиц $\mathrm{M}(\mathrm{C}, \mathrm{N})$ были обнаружены в изучаемой стали [15]. Первый тип -обогащенные $\mathrm{Nb}$ частицы округлой формы со средним размером 40 нм. Эти частицы выделяются при нормализации и отпуске до $500^{\circ} \mathrm{C}$ [2]. Второй тип - обогащенные ванадием частицы вытянутой формой и средним размером 20 нм, выделяются в процессе отпуска при $750^{\circ} \mathrm{C}$.

Механические свойства при ползучести. Зависимость приложенного напряжения от времени до разрушения представлена на рис. 1а. После испытаний на длительную прочность было обнаружено, что при температуре $650^{\circ} \mathrm{C}$ изучаемая сталь демонстрирует ярко-выраженный перелом на кривой длительной прочности при 2000 ч испытаний, в то время как при температуре $675^{\circ} \mathrm{C}$ на данный момент испытаний такого перелома нет. При этом перелом на кривой может появиться в зависимости от результата незавершенного испытания при 80 МПа (рис. 1а). Зависимости скорости ползучести от времени до разрушения при температурах 650 и $675^{\circ} \mathrm{C}$ представлены на рис. 16 и 1в соответственно. При температуре ползучести $650^{\circ} \mathrm{C}$ минимальная скорость ползучести составляет $1.2 \times 10^{-10} \mathrm{c}^{-1}$ при приложенном напряжении 100 МПа (рис. 1б). При снижении приложенных напряжений от 180 до 100 МПа время достижения минимальной скорости ползучести смещается с 47 до 3984 ч. При температуре ползучести $675^{\circ} \mathrm{C}$ минимальные скорости ползучести составляют $1.4 \times 10^{-8}$ и $4.6 \times 10^{-9} \mathrm{c}^{-1}$ при приложенном напряжении 120 и 100 МПа, соответственно (рис. 1в). При снижении приложенных напряжений от 160 МПа до 100 МПа время достижения минимальной скорости ползучести смещается с 10 до 1082 ч.

Карбонитриды М(C,N) после длительного отжига при 650 и $675^{\circ} \mathrm{C}$. Основным изменением в реечной структуре троостита отпуска изучаемой $9 \%$ Сr-стали в процессе длительного отжига при 650 и $675^{\circ} \mathrm{C}$ является выделение частиц фазы Лавеса со средним размером 100 нм [8] (рис. 2а). С увеличением времени отжига размеры карбидов $\mathrm{M}_{23} \mathrm{C}_{6}$ и фазы Лавеса увеличиваются в несколько раз [8], в то время как размеры карбонитридов $\mathrm{V}(\mathrm{C}, \mathrm{N})$ и $\mathrm{Nb}(\mathrm{C}, \mathrm{N})$ не меняются (рис. 2б), хотя и увеличились почти в 2 раза по сравнению с исходным со- 
стоянием (рис. 2б). Свидетельств образования частиц $Z$-фазы не было обнаружено после длительного отжига в течение 11151 ч при $650^{\circ} \mathrm{C}$ и 2003 ч при $675^{\circ} \mathrm{C}$. Незначительные изменения в химическом составе карбонитридов $\mathrm{M}(\mathrm{C}, \mathrm{N})$ были обнаружены после длительного отжига (рис. 2в). Так, в карбонитридах $\mathrm{V}(\mathrm{C}, \mathrm{N})$ увеличивается содержание ванадия и ниобия, и снижается содержание хрома (рис. 2в). В карбонитридах $\mathrm{Nb}(\mathrm{C}, \mathrm{N})$ содержание ниобия возрастает, в то время как содержание ванадия немного снижается (рис. 2в). Изменения в химическом составе мелких $\mathrm{M}(\mathrm{C}, \mathrm{N})$ карбонитридов не приводят к их трансформации в частицы $Z$-фазы.

Образование частиц $Z$-фазы после испытаний на длительную прочность при 650 и $675^{\circ} \mathrm{C}$. После долговременной ползучести в условиях $650^{\circ} \mathrm{C} / 120-$ 100 МПа структура троостита отпуска сильно эволюционирует, трансформируясь в субзеренную структуру со средним размером субзерна более 1.5 мкм, в то время как в условиях кратковременной ползучести $675^{\circ} \mathrm{C} / 120-100$ МПа сохраняется реечная структура со средним размером мартенситных реек около 500 нм [8]. Химический состав карбонитридов $\mathrm{Nb}(\mathrm{C}, \mathrm{N})$ значительно не меняется, свидетельств укрупнения этих частиц или их трансформации в частицы $Z$-фазы в процессе ползучести при обеих температурах не обнаружено. При этом в химическом составе карбонитридов $\mathrm{V}(\mathrm{C}, \mathrm{N})$ снижается доля ванадия и ниобия, возрастает доля хрома и железа, что ведет к их трансформации в частицы $Z$-фазы с составом 50 вес. \% $(\mathrm{Cr}+\mathrm{Fe})$ и 50 вес. \% $(\mathrm{V}+\mathrm{Nb})$, полученным методом энергодисперсионной спектрометрии, в условиях ползучести при обеих температуpax (рис. 3). При температуре $650^{\circ} \mathrm{C}$ несколько мелких частиц $Z$-фазы со средним размером 70 нм были обнаружены после 4869 ч испытания при приложенном напряжением 120 МПа [8, 15]. Существенное укрупнение частиц $Z$-фазы вплоть до 200 нм обнаружено после 11151 ч испытания на ползучесть при приложенном напряжении 100 МПа. Крупные частицы $Z$-фазы сосуществуют с карбонитридами $\mathrm{V}(\mathrm{C}, \mathrm{N})$ (рис. 3). Влияние локализации деформации на образование частиц $Z$-фазы было детально рассмотрено в [16]. Кратко можно отметить, что локализация ползучести меняет механизм зарождения частиц $Z$-фазы с прямой перестройки кубической решетки карбонитридов $\mathrm{V}(\mathrm{C}, \mathrm{N})$ в тетрагональную решетку $Z$-фазы в области равномерной деформации на гетерогенное зарождение частиц $Z$-фазы на границе $\mathrm{V}(\mathrm{C}, \mathrm{N}) /$ феррит. Присутствие одновременно очень мелких и крупных частиц ведет к ускоренному укрупнению частиц Z-фазы вблизи места разрушения.

Средний размер частиц $Z$-фазы достигал 300 нм в области, максимально близкой к разру- (a)

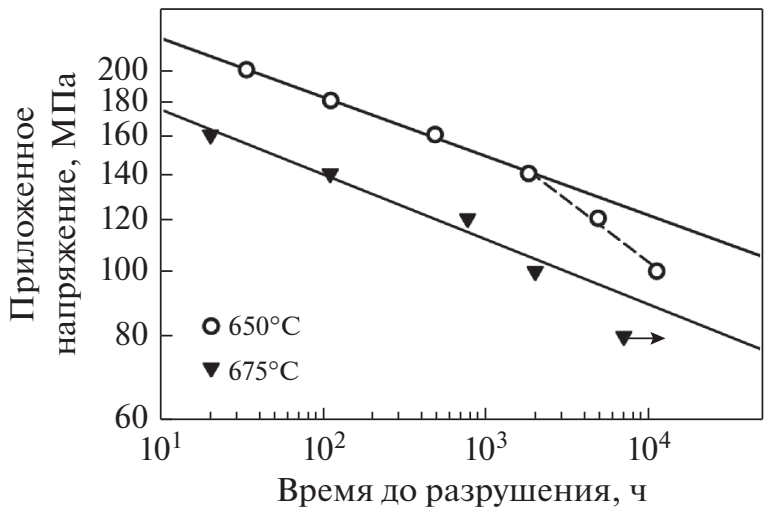

(б)

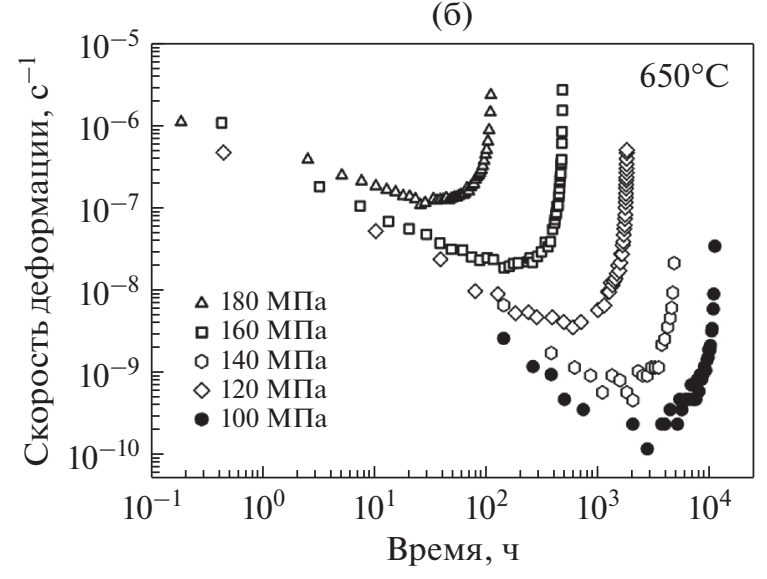

(в)

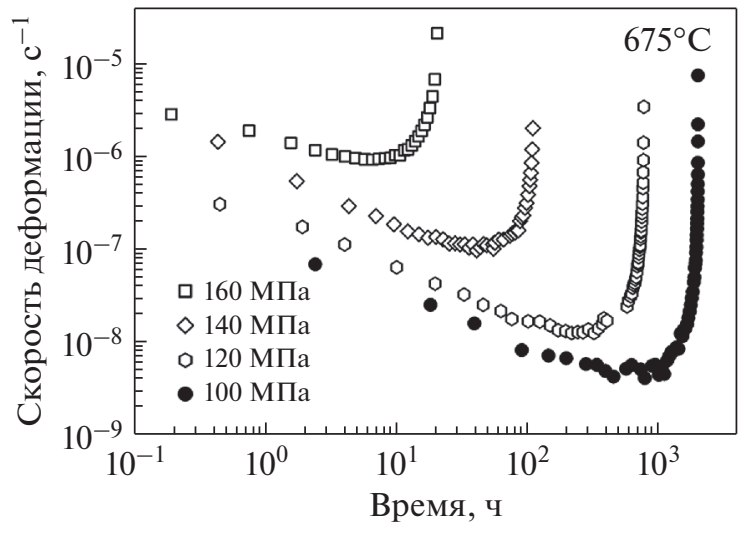

Рис. 1. Зависимость напряжения от времени до разрушения для изучаемой $9 \% \mathrm{Cr}$ стали, дополнительно легированной $3 \%$ Со, при температурах испытания 650 и $675^{\circ} \mathrm{C}(\mathrm{a})$, а также кривые зависимостей деформация-время $\left(б\right.$, в) при температуре $650^{\circ} \mathrm{C}$ и приложенных напряжениях 180, 160, 140, 120 и 100 МПа (б) и при температуре $675^{\circ} \mathrm{C}$ и приложенных напряжениях 160 , 140, 120 и 100 МПа (в).

шению. Соотношение частиц $Z$-фазы к V(C,N) изменялся от $1: 1$ в области равномерной деформации к $9: 1$ в области максимальной локализации пластического течения [16]. 


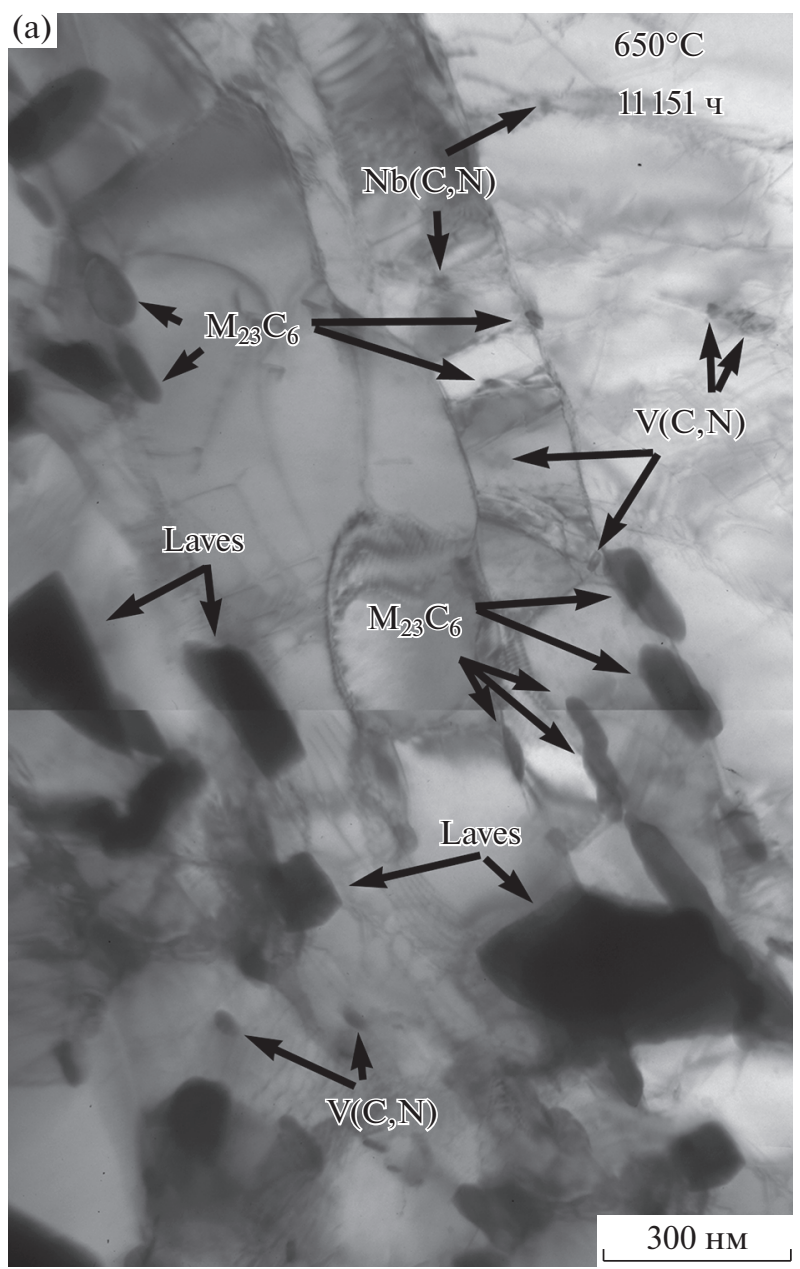

(б)
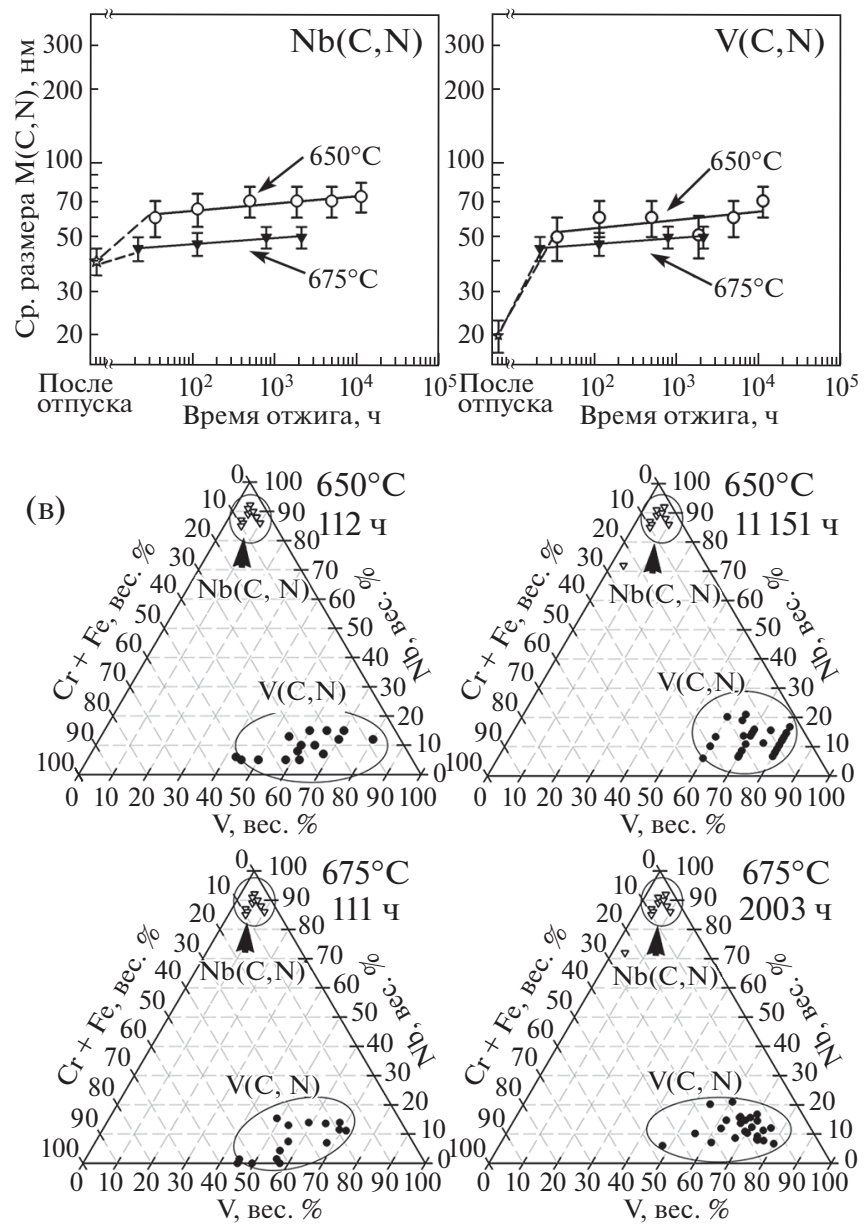

Рис. 2. Микроструктура изучаемой $9 \%$ Сr стали, дополнительно легированной $3 \%$ Со, в захватной части образца, испытанного на длительную прочность в условиях $650^{\circ} \mathrm{C}$ и $100 \mathrm{MПа,} \mathrm{время} \mathrm{до} \mathrm{разрушения} 11151$ ч (а); временная зависимость изменения размеров карбонитридов $\mathrm{Nb}(\mathrm{C}, \mathrm{N})$ и $\mathrm{V}(\mathrm{C}, \mathrm{N})$ при температурах отжига 650 и $675^{\circ} \mathrm{C}($ б); изменение химического состава карбонитридов $\mathrm{M}(\mathrm{C}, \mathrm{N})$ в процессе отжига при различных временах и температурах (в).

В условиях ползучести при температуре $675^{\circ} \mathrm{C}$ и приложенном напряжении 120 МПа, время до разрушения 773 ч, были обнаружены очень мелкие частицы $Z$-фазы на поверхности карбонитридов $\mathrm{V}(\mathrm{C}, \mathrm{N})$ с кубической решеткой в области локализации деформации (рис. 4). Увеличение времени ползучести (приложенное напряжение 100 МПа) до 2003 ч привело к укрупнению частиц $Z$-фазы с кубической решеткой до 41 нм и появлению отдельных частиц $Z$-фазы с тетрагональной решеткой со средним размером 60 нм с соотношением всех частиц $Z$-фазы к $\mathrm{V}(\mathrm{C}, \mathrm{N})$ как $1: 4$ (рис. 5) в области равномерной деформации. Отметим, что химический состав частиц $Z$-фазы с тетрагональной решеткой, образованной в процессе ползучести при $650^{\circ} \mathrm{C}$ (рис. Зг), и частиц $Z$-фазы с кубической решеткой и тетрагональной решеткой, образованной при $675^{\circ} \mathrm{C}$ ползучести (рис. 4б и 5г), одинаковый и не зависит ни от температуры, ни от типа кристаллической структуры.

\section{ОБСУЖДЕНИЕ РЕЗУЛЬТАТОВ}

Карбонитриды $\mathrm{Nb}(\mathrm{C}, \mathrm{N})$ стабильны в процессе ползучести. Размер этих частиц и их химический состав не меняются с увеличением температуры испытания, времени испытания или увеличения степени деформации, что говорит о высокой устойчивости данных карбонитридов против укрупнения при высокой температуре в процессе ползучести. Трансформации карбонитридов $\mathrm{Nb}(\mathrm{C}, \mathrm{N})$ в частицы $Z$-фазы также не было обнаружено. При этом карбонитрид $\mathrm{V}(\mathrm{C}, \mathrm{N})$ не является стабильной фазой при $T=650$ и $675^{\circ} \mathrm{C}$. Согласно термодинамике, существование нестабильных фаз в сплаве не отвечает минимальному значению энергии Гиббса $[16,17]$ и, следовательно, должны раствориться. Расчеты с помощью программы Thermo-Calc показывают, что равновесной фазой при 650 и $675^{\circ} \mathrm{C}$ является $Z$-фаза с химическим составом $50 \%(\mathrm{Cr}+\mathrm{Fe})$ и $50 \%(\mathrm{~V}+\mathrm{Nb})$. Это согласуется с данными работ [5, 12, 13], что 


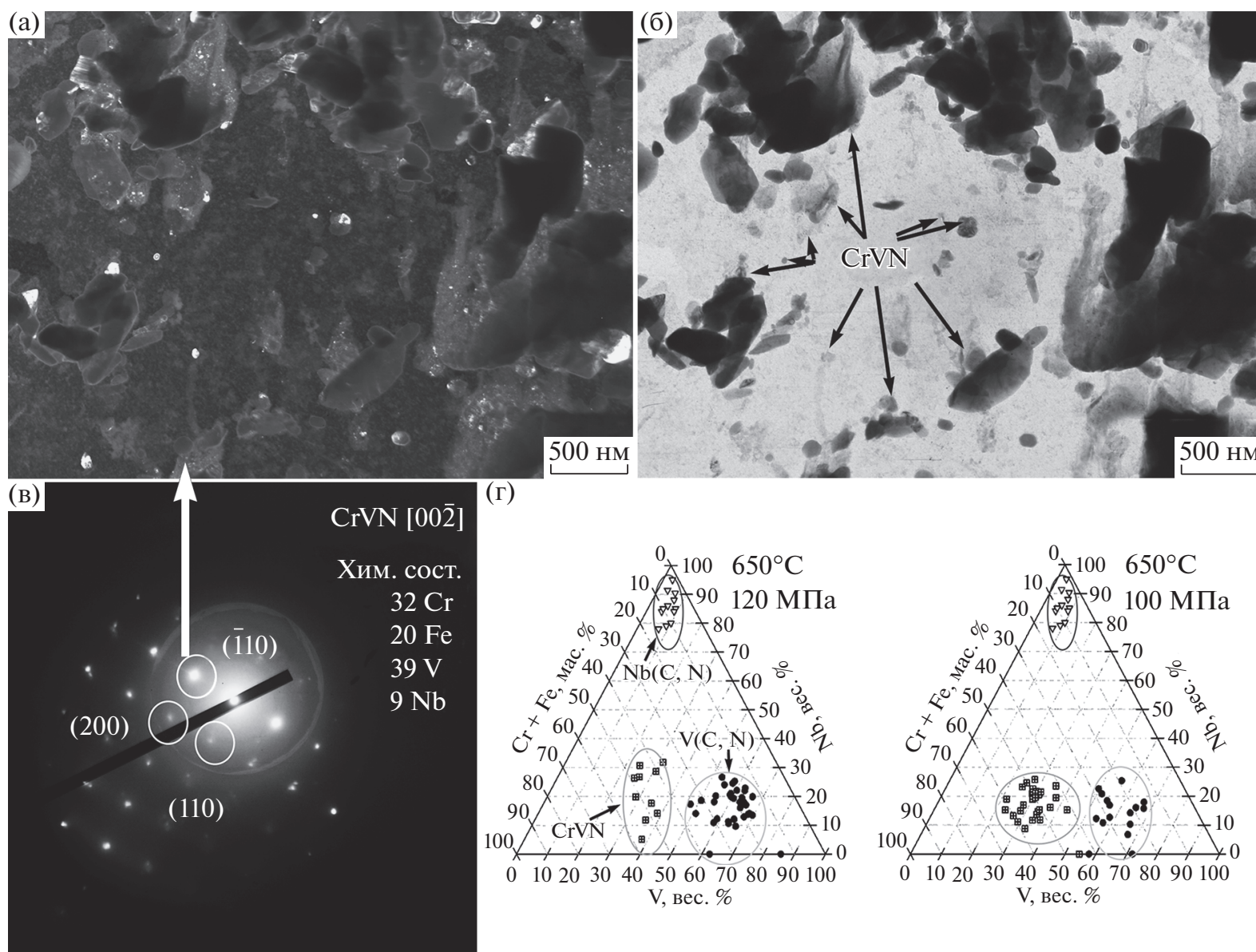

Рис. 3. Темнопольное (а) и светлопольное (б) ПЭМ изображения частиц $Z$-фазы, полученные с рефлекса (-110) (в) после ползучести в условиях $650^{\circ} \mathrm{C} / 100$ МПа в области локализации деформации; изменение химического состава карбонитридов М $(\mathrm{C}, \mathrm{N})$ и частиц $Z$-фазы в процессе ползучести при $650^{\circ} \mathrm{C}$ и напряжениях 120 и $100 \mathrm{MПа} \mathrm{(в).}$
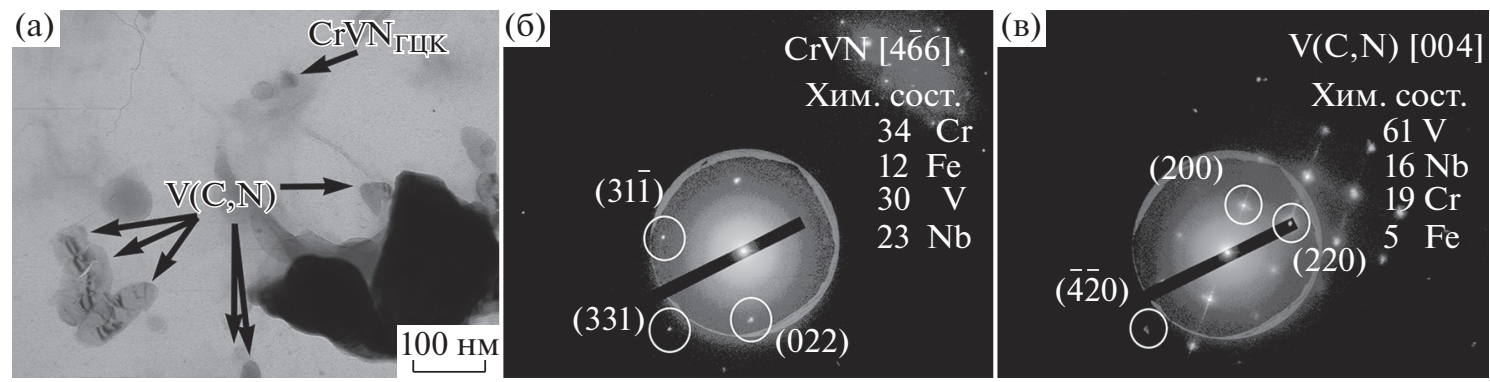

Рис. 4. Светлопольное ПЭМ изображение частиц $Z$-фазы и карбонитридов V(C,N) (a) с соответствующими электронограммами от частицы $Z$-фазы с кубической решеткой (б) и карбонитрида $\mathrm{V}(\mathrm{C}, \mathrm{N})$ (в) в условиях ползучести $675^{\circ} \mathrm{C} / 120 \mathrm{M \Pi а}$.

$Z$-фаза - это самый стабильный нитрид в 9$11 \%$ Сr-сталях. При этом количество $Z$-фазы зависит от температуры и времени выдержки, а также от содержания Сr в стали [4]. При обеих температурах ползучести при 650 и $675^{\circ} \mathrm{C}$ наблюдается процесс трансформации мелких $\mathrm{V}(\mathrm{C}, \mathrm{N})$ частиц в $Z$-фазу.
Следует отметить, что образование частиц $Z$-фазы незначительно влияет на механическое поведение изучаемой стали и не приводит к появлению перелома на кривой длительной прочности при температуре $675^{\circ} \mathrm{C}$ (рис. 1а). При этом в ранних исследованиях было установлено, что при температуре $650^{\circ} \mathrm{C}$ появление перелома на кри- 

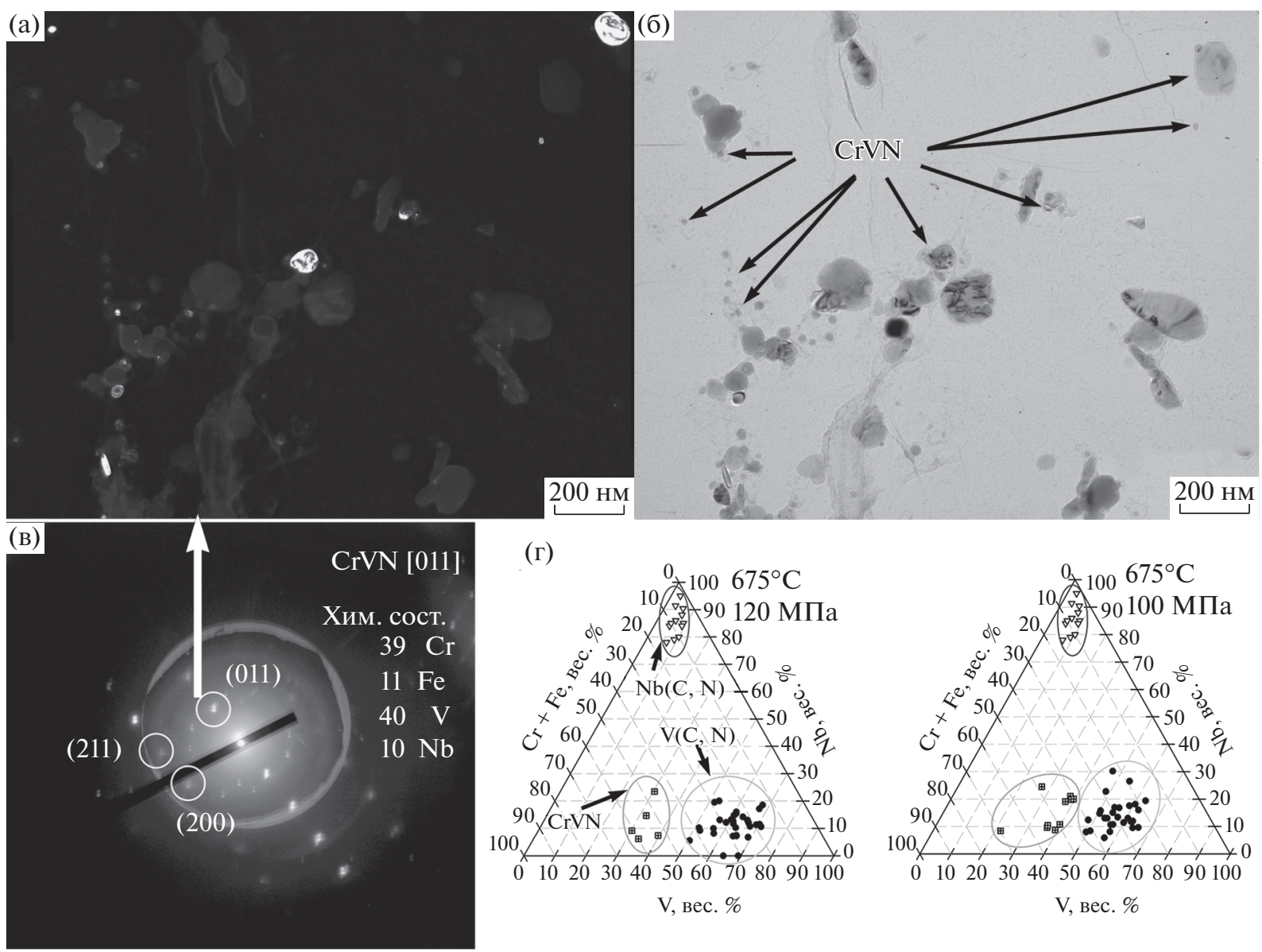

$(\Gamma)$
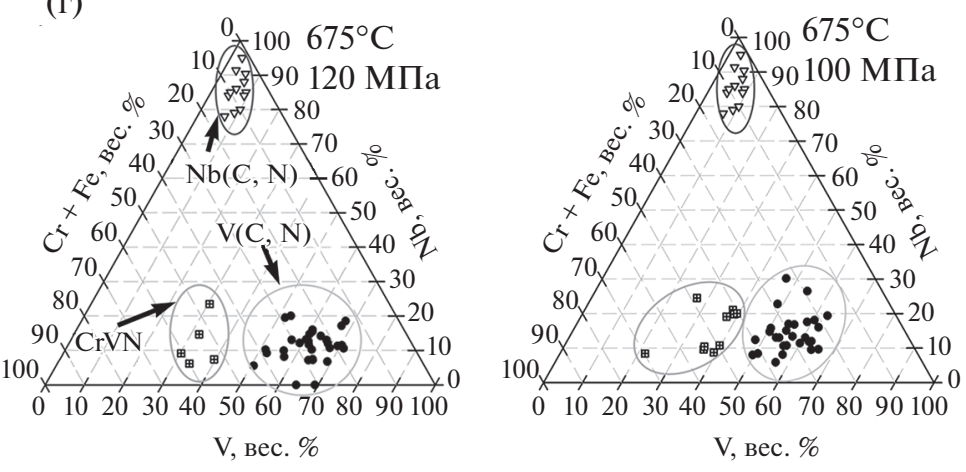

Рис. 5. Темнопольное (а) и светлопольное (б) ПЭМ изображения частиц $Z$-фазы, полученные с рефлекса (011) (в) после ползучести в условиях $675^{\circ} \mathrm{C} / 100$ МПа в области равномерной деформации; изменение химического состава карбонитридов $\mathrm{M}(\mathrm{C}, \mathrm{N})$ и частиц $Z$-фазы в процессе ползучести при $675^{\circ} \mathrm{C}$ и напряжениях 120 и $100 \mathrm{MПа} \mathrm{(г).}$

вой длительной прочности вызвано другими структурными изменениями в микроструктуре исследуемой стали [8]. Замещение карбонитридов $\mathrm{V}(\mathrm{C}, \mathrm{N})$ на $Z$-фазу не сказывается на наклоне кривой в области третичной стадии ползучести при обеих температурах 650 и $675^{\circ} \mathrm{C}$ при снижении приложенного напряжения (рис. 16, 1в). Отсутствие изменений наклона кривой в области третичной стадии ползучести при снижении приложенного напряжения свидетельствует о том, что образование частиц $Z$-фазы не вносит существенный вклад в деградацию структуры, если сохраняется хотя бы $50 \%$ карбонитридов $\mathrm{V}(\mathrm{C}, \mathrm{N})$ от исходного количества [15].

В работах $[6,7,18]$ было показано, что мелкие частицы $Z$-фазы не оказывают негативного эффекта на длительную прочность в $12 \% \mathrm{Cr}$ сталях, в то время как появление перелома на кривых длительной прочности независимо от температуры испытания связано с укрупнением частиц $Z$-фазы. Чем выше доля этих крупных частиц, тем сильнее наклон кривой длительной прочности и ниже предел длительной прочности.
Снижение приложенного напряжения и, соответственно, увеличение времени ползучести стимулируют образование частиц $Z$-фазы, вызывая укрупнение этой фазы. При этом увеличение температуры испытания вызывает образование зародышей частиц $Z$-фазы за более короткие времена ползучести в изученной мартенситной стали (рис. 4). Так, повышение температуры на $25^{\circ} \mathrm{C}$ уменьшило время до начала зарождения частиц $Z$-фазы почти в пять раз. Добавление деформации к высокой температуре при ползучести вызывает образование зародышей частиц $Z$-фазы независимо от температуры испытания. Так, при температуре ползучести $650^{\circ} \mathrm{C}$ трансформация карбонитридов $\mathrm{V}(\mathrm{C}, \mathrm{N})$ в частицы $Z$-фазы была зафиксирована при приложенном напряжении 120 МПа только в деформированной рабочей части образца, в то время как в области захватов, где идет длительное старение без пластической деформации, частиц $Z$-фазы не обнаружено. При температуре ползучести $675^{\circ} \mathrm{C}$ начало трансформации карбонитридов $\mathrm{V}(\mathrm{C}, \mathrm{N})$ в частицы $Z$-фазы было зафиксировано при приложен- 
ном напряжении 120 МПа в области локализации деформации образца (рис. 4) и развитие этого превращения идет со снижением приложенного напряжения до $100 \mathrm{MПа,} \mathrm{распространяясь} \mathrm{и} \mathrm{в} \mathrm{область}$ равномерной деформации образца (рис. 5). В то же время в области захватов образцов частиц $Z$ фазы не обнаружено. Длительный отжиг приводит к стабилизации частиц $\mathrm{V}(\mathrm{C}, \mathrm{N})$ без трансформации в $Z$-фазу (рис. 2). Именно пластическая деформация способствует замещению менее стабильной фазы $\mathrm{V}(\mathrm{C}, \mathrm{N})$ на более стабильную $Z$-фазу, поскольку в отсутствие таковой, ванадиевые частицы стабильны как в размерах, так и в химическом составе. Они остаются неизменными достаточно длительное время независимо от температуры испытания. Замедлить или устранить образование частиц возможно либо снижением температуры эксплуатации, что является неприемлемым, либо изменением схемы легирования путем снижения количества азота, что требует изменения схемы выплавки стали вакуумно-индукционным или вакуумно-дуговым методами.

\section{ЗАКЛЮЧЕНИЕ}

Пластическая деформация играет ключевую роль в образовании частиц $Z$-фазы, которые появляются только в процессе ползучести. Повышение степени деформации сильно повышает удельный объем $Z$-фазы и приводит к ее укрупнению. Чем меньше прикладываемое напряжение и, соответственно, выше время до разрушения, тем интенсивнее протекает процесс образования частиц $Z$-фазы. Чем выше температура испытания, тем за более короткое время протекает процесс образования частиц $Z$-фазы, при этом механизм образования частиц зависит от температуры.

Работа выполнена за счет средств гранта РФФИ № 18-38-00002 “мол_а”. Авторы выражают благодарность центру коллективного пользования “Технологии и Материалы НИУ “БелГУ” за предоставленное оборудование для проведения структурных исследований.

\section{СПИСОК ЛИТЕРАТУРЫ}

1. Abe F., Kern T.U., Viswanathan R. Creep-resistant steels. Woodhead: Publishing, Cambridge, 2008. 800 p.

2. Kipelova, Yu., Belyakov A.N., Skorobogatykh V.N., Shchenkova I.A., Kaibyshev R.O. Tempering-induced structural changes in steel $10 \mathrm{Kh} 9 \mathrm{~K} 3 \mathrm{~V} 1 \mathrm{M} 1 \mathrm{FBR}$ and their effect on mechanical properties // Metal Sci. Heat Treatment. 2010. V. 52 P. 100-110.

3. Di Gianfrancesco A. Materials for Ultra-Supercritical and Advanced Ultra-Supercritical Power Plants, Woodhead: Publishing, Cambridge, 2017. 900 p.
4. Strang A., Vodarek $V . \mathrm{Z}$ phase formation in martensitic 12CrMoVNb steel // J. Mater. Sci. Techn. 1996. V. 12. P. 552-556.

5. Danielsen H.K., Di Nunzio P.E., Hald J. Kinetics of Z-phase precipitation in 9 to 12 pct Cr steels // Metall. Mater. Trans. A. 2013. V. 44A. P. 2445-2452.

6. Кайбышев Р.О., Скоробогатых В.Н., Щенкова И.А. Формирование $Z$-фазы и перспективы применения сталей мартенситного класса с $11 \% \mathrm{Cr}$ для работы при температурах выше $590^{\circ} \mathrm{C} / /$ Металловедение и терм. обр. металлов. 2010. Т. 3. С. 4-14.

7. Suzuki K., Kumai S., Toda Y., Kushima H., Kimura K., Two-phase separation of primary MX carbonitrides during tempering in creep resistant $9 \mathrm{Cr} 1 \mathrm{MoVNb}$ steel, Iron and Steel Institute Japan International. 2003. V. 43 P.1089-1094.

8. Fedoseeva A., Dudova N., Kaibyshev R. Creep strength breakdown and microstructure evolution in a $3 \% \mathrm{Co}$ modified P92 steel // Mater. Sci. Eng. A. 2016. V. 654. P. 1-12.

9. Fedoseeva A., Dudova N., Kaibyshev R. Effect of Tungsten on a Dispersion of $\mathrm{M}(\mathrm{C}, \mathrm{N})$ Carbonitrides in $9 \%$ Cr Steels Under Creep Conditions // Trans. Indian Institute of Metals. 2016. V. 69. P. 211-215.

10. Кайбышев Р.О., Скоробогатых В.Н., Щенкова И.А. Новые стали мартенситного класса для тепловой энергетики. Жаропрочные свойства // ФММ. 2010. T. 109. C. 200-215.

11. Letofsky-Papst I., Warbichler P., Hofer F., Letofsky E., Cerjak $H$. On the occurrence of Z-phase in a creep-tested 10\% Cr steel // Zeitschrift für Metallkunde. 2004. V. 95. P. 18-21.

12. Danielsen H.K., Hald J. On the nucleation and dissolution process of $Z$-phase $\mathrm{Cr}(\mathrm{V}, \mathrm{Nb}) \mathrm{N}$ in martensitic $12 \% \mathrm{Cr}$ steels // Mater. Sci. Eng. A. 2009. V. 505. P. 169-177.

13. Danielsen H.K. Review of $\mathrm{Z}$ phase precipitation in $9-$ 12 wt \% Cr steels // J. Mater. Sci. Techn. 2016. V. 32. P. 126-137.

14. Dudova N., Mishnev R., Kaibyshev R. Creep behavior of a $10 \% \mathrm{Cr}$ heat-resistant martensitic steel with low nitrogen and high boron contents at $650^{\circ} \mathrm{C} / /$ Mater. Sci. Eng. A. 2019. V. 766. № 138353.

15. Федосеева А.Э., Никитин И.С., Дудова Н.Р., Кайбышев P.O. Об особенностях образования частиц $Z$-фазы в мартенситной стали, содержащей $9 \% \mathrm{Cr}$, в процессе ползучести при $650^{\circ} \mathrm{C}$ и их влиянии на ползучесть // Деформация и разрушение материалов. 2019. № 3. С. 8-15.

16. Fedoseeva A., Nikitin I., Dudova N., Kaibyshev $R$. Strain-induced Z-phase formation in a $9 \% \mathrm{Cr}-3 \% \mathrm{Co}$ martensitic steel during creep at elevated temperature // Mater. Sci. Eng. A. 2018. V. 724. P. 29-36.

17. Попов В.В. Моделирование превращений карбонитридов при термической обработке сталей. УрО РАН, Екатеринбург, 2003. 378 с.

18. Sawada K., Kushima H., Kimura K., Tabuchi M. $Z$-phase formation and its effect on long-term creep strength in 9-12\% Cr creep resistant steels // Trans. Indian Institute of Metals. 2010. V. 63. P. 117-122. 